\title{
ARTIGOS
}

\section{APROVEITAMENTO ENERGÉTICO ATRAVÉS DO BIODIGESTOR E SUA IMPLANTAÇÃO EM PRÉDIOS DE 20 ANDARES}

\section{ENERGY UTILIZATION THROUGH THE BIODIGESTER AND ITS IMPLANTATION IN BUILDINGS OF 20 FLOORS}

ROSALES BEZERRA | UEPB

LUIS REYES ROSALES MONTERO, DR. | UFCG

VALDERI DUARTE LEITE, DR. |UEPB

KELLY DAYANE SILVA DO Ó, M.SC. |UEPB

\begin{abstract}
RESUMO
A atual civilização humana tem usufruído em demasia dos recursos energéticos não renováveis, comprometendo assim a sustentabilidade do meio ambiente. Projetos envolvendo práticas de equilíbrio ambiental devem ser mais intensificados nas obras da engenharia moderna, com finalidade principal, reaproveitamento de resíduos produzidos pelo homem em decorrência do seu elevado poder de consumo. O intuito deste artigo consiste em adequar modelos de biodigestores a prédios de 20 andares, possibilitando assim o reaproveitamento dos resíduos orgânicos prediais para posterior conversão energética, na utilização de energia renovável, além da redução dos gastos financeiros com energia elétrica.
\end{abstract}

PALAVRAS-CHAVE: Resíduos, Energia, Biodigestor, Biogás.

\begin{abstract}
The present human civilization has enjoyed too much of the non-renewable energy resources, thus compromising the sustainability of the environment. Projects involving environmental equilibrium practices should be further intensified in the works of modern engineering, in order to seek the reuse of man-made matter as a result of its high consumption power. The purpose of this article is to adapt models of biodigestors to 20-storey buildings, thus making it possible to reuse solid waste for later conversion into energy, which can be used in the routine activities of the inhabitants, as well as a good reduction of energy expenditures.
\end{abstract}

KEYWORDS: Waste, Energy, Biodigester, Biogas. 


\section{INTRODUÇÃO}

\subsection{Panorama energético nacional}

Até o início do século $X X$, a biomassa era tida como a principal fonte energética. Foi quando se teve início a chamada "era do petróleo" e a biomassa energética ficou praticamente esquecida. Segundo Staiss; Pereira (2001) os elementos primários da biomassa podem ser convertidos através de diferentes tecnologias em bicombustíveis sólidos, líquidos ou gasosos, que por sua vez se transformam em energias térmica, mecânica e elétrica.

A produção de energia elétrica a partir da biomassa, atualmente, é proposta como uma alternativa importante para países em desenvolvimento. Considerado um dos principais causadores de problemas ambientais no agronegócio, os dejetos gerados da criação de animais estão sendo reaproveitados para a geração de gás combustível e biofertilizante, onde esta matéria orgânica é utilizada como substrato para bactérias metanogênicas (bactérias formadoras de gás metano) responsáveis pela produção de biogás.

O Brasil, é privilegiado por apresentar alternativas para geração de energia renovável, o país possui extenso território litorâneo que possibilita potencial energético a partir de energia eólica, retrata também viabilidade para produção de energia solar, visto que o Brasil apresenta intensa radiação solar na maior parte do ano, em quase todos os estados, utilização dos vastos rios para a obtenção de energia hídrica, e produção de energia advinda da biomassa, uma vez que o país detém grande criação de animais. Conforme o IBGE(2017), o Brasil é o maior criador de gado bovino no mundo, ultrapassando a marca de 218,2 milhões de cabeças.

O Brasil produz 195 mil toneladas de resíduos sólidos urbanos por dia, conforme dados da ABRELPE(2016). Embora o excesso de resíduos sólidos urbanos seja problema, seu manejo, devidamente administrado, poderá ser transformado em potencial econômico. O gerenciamento integrado de resíduos sólidos urbanos favorece ao saneamento básico e possui a capacidade de conversão energética. Na figura 1, apresenta dados da atual distribuição do destino final do RSU brasileiro. Caso este fosse totalmente aproveitado, estima-se que o potencial de geração de energia de todo o lixo seria suficiente para abastecer em $30 \%$ a demanda de energia elétrica atual do Brasil.

\section{Destino do lixo no Brasil}

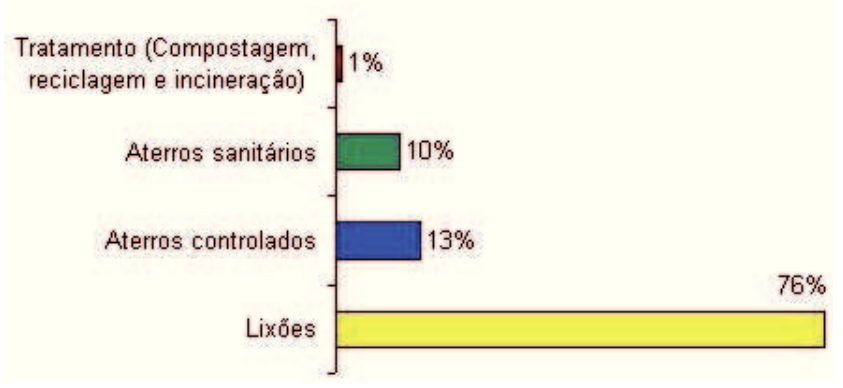

Figura 1:Destino final dos resíduos sólidos urbanos (RSU) no Brasil Fonte: CEMPRE,(2017)

O desenvolvimento de tecnologias para geração de energia a partir de Resíduos Sólidos Urbanos (RSU) é adequado principalmente para grandes centros urbanos, uma vez que a quantidade de RSU gerados por dia, denota grande perspectiva de produção energética, e proporciona destinação adequada de resíduos. Historicamente, resíduos foram destruídos em incineradores, porém devido a emissões de poluentes e alto custo de tratamento, esta prática tem se tornado cada vez menos comum, dando lugar a novas formas de aproveitamento de resíduos sustentáveis, tanto economicamente como ambientalmente.

A energia sempre foi reconhecida como a base do desenvolvimento das civilizações. No final do século XIX, por exemplo, o mundo modernizou após a Revolução Industrial, principalmente devido às novas fontes de energia. De acordo Alves (2009), relata as fontes de energia podem ser classificadas em renováveis, conhecidas também como energia limpa, exemplo da energia solar, eólica, biomassa e a hídrica, que obtêm repostas da natureza relativamente curtos em período de tempo e as não renováveis, uma vez que não podem ser regeneradas e sua reposição na natureza pode levar milhões de anos, ou simplesmente, não mais ocorrer.

As energias renováveis está em crescimento acelerado nos últimos anos, favorecendo assim seu desenvolvimento, disseminação e aplicação, tornando-se uma alternativa totalmente viável para a atual situação mundial, com as crises de petróleo nos países produtores, grande fragilidade do sistema de hidroelétricas, que ocasionou os últimos apagões no Brasil, inviabilidade e perigo de construção de termelétricas, usinas nucleares e outras formas de energia suja, chamadas desta forma, pois a utilização das mesmas gera uma grande carga de poluentes e, consequente degradação ambiental, o qual é visível e notório do ponto de vista social, econômico e humano(SILVA ,2009) 
Na figura 2, estão apresentados os dados da energia no país, de acordo com dados obtidos da. Vale ressaltar que esse atual quadro energético brasileiro é muito bom comparado ao quadro energético mundial, isto porque o nosso país é um dos que mais usufruem da energia limpa em todo o mundo. Contudo, ainda há a necessidade de crescimento de outras fontes, principalmente da biomassa.

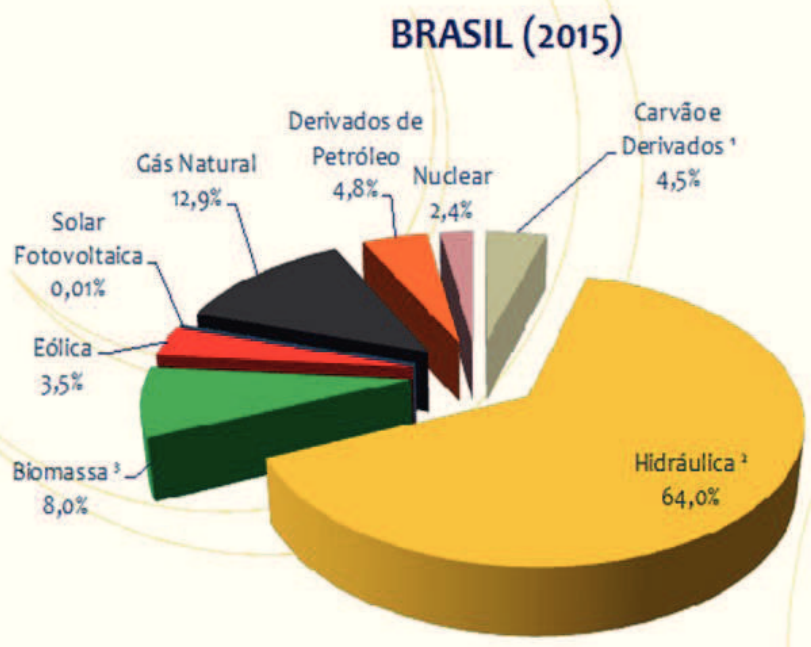

Figura 2:Produção interna de energia elétrica no Brasil Fonte:Aneel(2016)

A necessidade de atender a demanda energética nas diversas áreas causando o mínimo de impacto, seja ele social ou ambiental, faz surgir a busca e exploração de fontes energéticas alternativas. O Governo Federal busca iniciativas para renovar essas fontes energéticas.

Outro fator importante a ser considerado é as hidrelétricas, importante para a geração de energia elétrica no país, também serão afetadas pelas mudanças climáticas, tendo em vista que os ciclos hidrológicos no planeta já começaram a ser alterados. Assim, o Brasil necessita diversificar a matriz energética e ampliar a utilização de outras fontes de energia renováveis no país, tais como energia solar, eólica, biomassa e biogás.

\subsection{Conceitos gerais do biodigestor e seu pro- cesso produtivo}

Os biodigestores tem sido alvo de grande destaque tendo em vista a crise de energia e consequente busca por fontes alternativas, ressaltando que os biodigestores são importantes no intenso processo de modernização da agropecuária, que demanda energia e gera resíduos animais e de culturas que pode ocasionar problemas de ordem sanitária. O biogás pode ser usado como combustível em substituição ao gás natural (GNV) ou ao gás liquefeito de petróleo (GLP), ambos extraídos de reservas minerais. O biogás pode ser utilizado para cozinhar em residências rurais próximas ao local de produção (economizando outras fontes de energia, como principalmente lenha ou GLP).

Segundo Barrera (1993), um biodigestor constitui-se de uma câmara fechada onde é colocado o material orgânico, em solução aquosa, para sofrer decomposição, gerando o biogás que irá se acumular na parte superior da referida câmara. A decomposição que o material sofre no interior do biodigestor, com a consequente geração de biogás, chama-se digestão anaeróbica. Com base nos consumos médios de biogás das diversas utilidades que se deseja instalar em uma propriedade, podemos determinar o volume de biogás diário suficiente para suprir as necessidades da propriedade. Existe, atualmente, uma gama muito grande de modelos de biodigestores, sendo cada um adaptado a uma realidade e uma necessidade de biogás.

Na figura 3, temos uma representação de um biodigestor de modelo tradicional instalado em pequena propriedade rural. Observe que o equipamento segue determinadas normas de instalação de modo a não oferecer riscos humanos. Normalmente, sua instalação ocorre longe de áreas trafegáveis, pois um possível escape do biogás pode desencadear alguns tipos de danos indesejáveis à saúde humana.

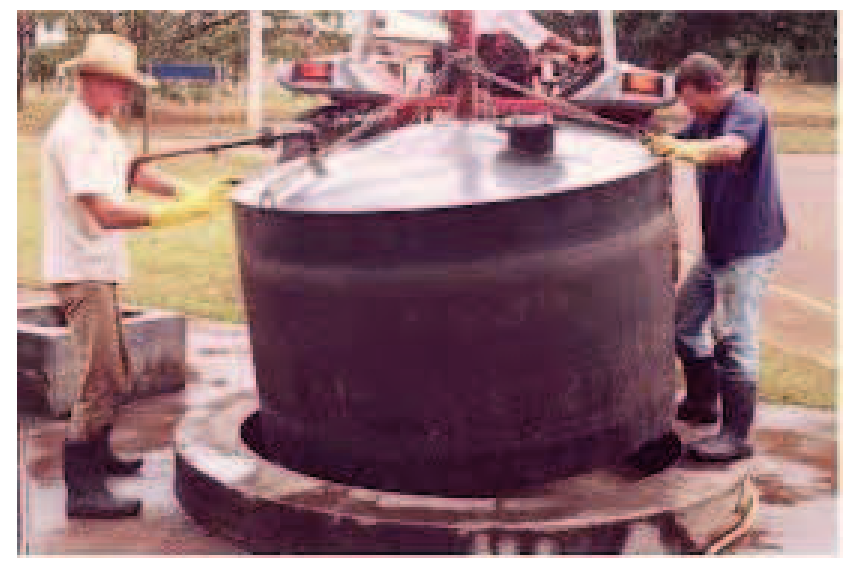

Figura 3: Instalação de aparelho biodigestor em pequena propriedade Fonte: EMBRAPA

O biodigestor é um tanque protegido, sem entrada de ar atmosférico que gera subproduto, Biogás. O efluente mineralizado após o tratamento, apresenta carga orgânica reduzida, e pode ser aplicado para produção de microalgas, servindo assim de insumo para a cultura de peixes. $O$ biodigestor possui grande aplicação na agropecuária, para manejo integrado dos dejetos dos animais, aproveitando-os como fontes energéticas. 
Existe três modelos principais de biodigestores, que executam praticamente as mesmas funções, sem grandes variações: o modelo chinês, indiano e a batelada. $\mathrm{Na}$ figura 4, apresenta o modelo esquemático do biodigestor Chinês.

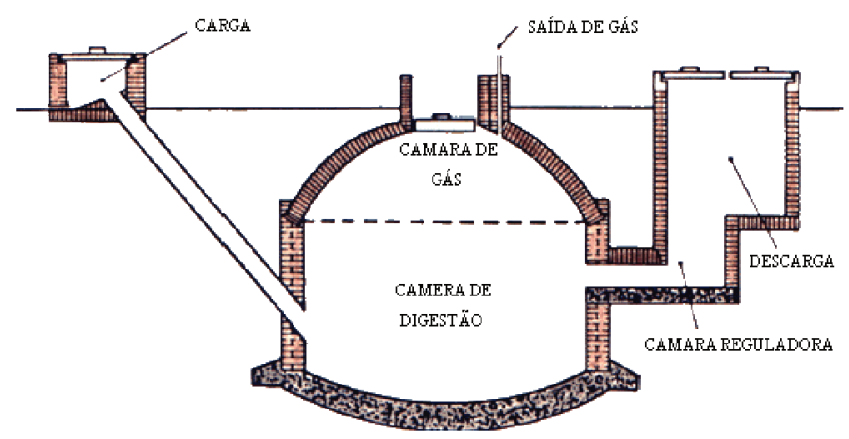

Figura 4:Biodigestor modelo chinês. Fonte: DEGANUTTI( 2002)

No modelo chinês, visto na figura 4, a cúpula é fixa, de alvenaria, guarnecida por uma espécie de válvula, composta por uma tampa e pressionada por um depósito de água. A característica desse modelo exige que se esgote o gás com mais frequência, a fim de evitar tanto o impacto ambiental negativo pelo lançamento do biogás direto na
5, está presente o modelo biodigestor Indiano

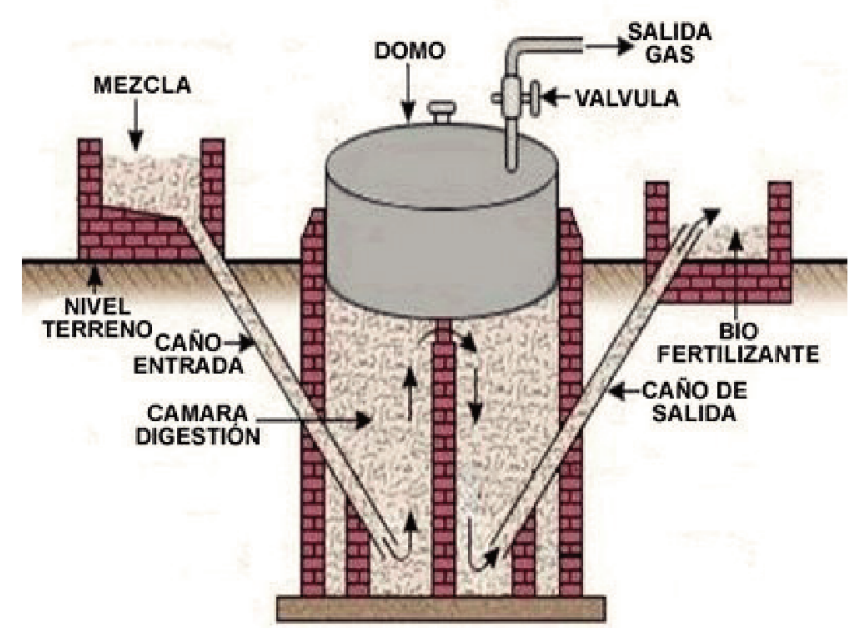

Figura 5: Biodigestor anaeróbio modelo indiano Fonte: DEGANUTTI( 2002)

Este modelo de biodigestor caracteriza-se por possuir uma campânula como gasômetro, a qual pode estar mergulhada sobre a biomassa em fermentação, ou em um selo d'água externo, e uma parede central que divide o tanque de fermentação em duas câmaras. A função da parede divisória faz com que o material circule por todo o interior da câmara de fermentação.(DEGANUTTI,2002)

Os sistemas de bateladas sequenciais são tecnologicamente mais simples, robustos e baratos, tendo como principais desvantagens, a necessidade de uma maior área e uma menor produtividade de biogás. Entretanto, devido aos reatores serem completamente esvaziados ao final de cada processo, torna-se possivel eliminar um dos principais problemas operacionais enfrentados em usinas de biodigestores de fração orgânica de resíduos sólidos urbanos, o acúmulo de materiais inertes no interior do reator (DE BAERE;MATTHEEUWS, 2008).

Na Figura 7, estão apresentadas as etapas do processo de digestão anaeróbia, resumido em cinco etapas: Hidrólise, acidogênese, acetogênese e metanogêneses e sulfetogênese, como também os grupos microbianos envolvidos no processo.

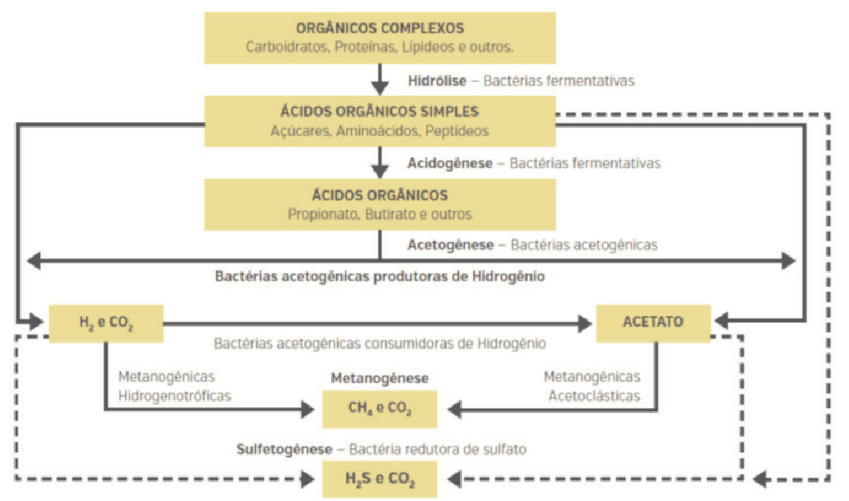

Figura 7:Processo de digestão anaeróbia (Fonte: CHERNICHARO,1997)

As bactérias metanogênicas desempenham duas funções primordiais: elas produzem gás insolúvel (o metano) possibilitando a remoção do carbono orgânico do ambiente anaeróbio, além de utilizarem o hidrogênio, favorecendo o ambiente para que as bactérias acidogênicas fermentem compostos orgânicos com a produção de ácido acético, o qual é convertido em metano. A digestão anaeróbia de compostos orgânicos é considerada um processo de dois estágios. No primeiro, um grupo de bactérias facultativas e anaeróbias, denominadas fermentativas, convertem os orgânicos complexos em outros compostos.(CHERNICHARO,1997)

\section{METODOLOGIA}

\subsection{Características do projeto}

O estudo aborda a incorporação de sistemas de biodigestores em prédios de 20 andares (Figura 9), visando a sustentabilidade ambiental e econômica, utilizando métodos capazes de transformar os resíduos sólidos orgânicos 
em fonte de energia para a sociedade. O prédio utilizado como modelo, para desenvolvimento do projeto é localizado em cidade com grande população urbana, classe média alta, com 20(vinte) andares com 2 (dois) apartamentos por andar, no total de 40 (quarenta) apartamentos, o qual residem aproximadamente 160 moradores.

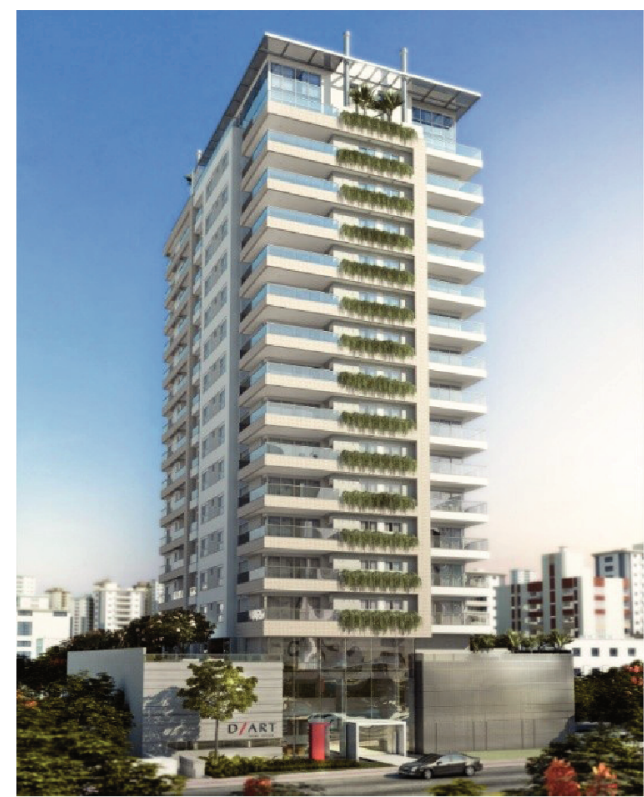

Figura 9: Representação de um prédio de 20 andares Fonte: Dimasconstruções,(2016)

Para identificar a quantidade de biogás foi utilizado o fator de conversão $0,038 \mathrm{~m} 3$ de biogás é capaz de produz a partir de um metro cúbico de biogás, utilizado por Costa, (2006) em seu experimento para produção de eletricidade a partir de esgoto doméstico.

Existe diversas alternativas para viabilizar o aproveitamento do biogás advindo dos biodigestores. No quadro 1, são apresentados os dados relacionados a equivalência energética do biogás, é possível observar que para geração de 1,43 kWh de energia elétrica é necessário um m3 de biogás.

\begin{tabular}{|l|l|}
\hline Fonte & Faixa \\
\hline Gasolina(L) & $0,61-0,70$ \\
\hline Querosene(L) & $0,58-0,62$ \\
\hline Óleo Diesel(L) & 0,55 \\
\hline GLP(kg) & $0,40-1,43$ \\
\hline Álcool(L) & 0,80 \\
\hline Carvão Mineral & 0,74 \\
\hline Lenha(kg) & 3,50 \\
\hline Eletricidade(kWh) & $1,25-1,43$ \\
\hline
\end{tabular}

Quadro 1 -Equivalências energéticas entre fontes de energia e um $\mathrm{m}^{3}$ de Biogás Fonte: Pompermayer, (2000)
Sistema deste projeto é constituído de quatro unidades distintas, sendo:

1) Digestão Anaeróbia - que engloba as caixas de entrada e saída de resíduos. Os tanques de pré-fermentação e o tanque do biodigestor.

2) Armazenamento e Processamento dos Resíduos Digeridos - nesta unidade pode-se ter tanques de armazenamento e deságue dos resíduos, prensas, secadores, ensacadores, etc.

3) Armazenamento e Purificação de Gás - para este caso há filtros de remoção de gases de enxofre, umidade, dióxido de carbono. Também há armazenadores de gases.

4) Co-Geração de Energia - unidade geradora de energia térmica, motriz e elétrica, através do gás gerado pelo Biodigestor. Neste caso deve ter motogeradores, turbogeradores, caldeiras, etc, que será dimensionada pela equipe técnica da Ultrapuro (parceiro do projeto).

\begin{tabular}{|c|c|}
\hline Biogás necessário $\left(\mathrm{m}^{3}\right)$ & 14,43 \\
\hline Caixa d'água $(\mathrm{L})$ & 5000,00 \\
\hline Diâmetro $\operatorname{lnt}(\mathrm{m})$ & 2,00 \\
\hline Profundidade $(\mathrm{m})$ & 2,80 \\
\hline Quantidade (unidade) & 6,00 \\
\hline Custo estimado (R\$) & 24440,05 \\
\hline
\end{tabular}

Figura 11: Exemplificação de custo de biodigestor para prédios (Fonte: ULTRAPUR0, 2009)

Segundo Junior(2009), é possível estimar a geração de resíduos sólidos domiciliares a partir de indicadores de consumo do edifício, além da própria população. Dentre os indicadores de consumo (consumo de água e consumo de energia elétrica), apenas o consumo de água serviu para tal estimativa, utilizou-se o seguinte modelo matemático para estimar a quantidade de resíduos sólidos gerados em um prédio:

\section{MRSD $=0$, 0697 POP $+2,28$ CA - 7,25 (equação I)}

\section{Onde:}

MRSD: massa de resíduos sólidos domiciliares (m3/dia); POP: população do edifício (habitantes);

CA: consumo de água ( $\left.\mathrm{m}^{3} / \mathrm{dia}\right)$.

A equação I é útil para o projeto, visto que apresenta a estimativa da produção de resíduos diários, sendo utilizado na projeção dos dados., além da maior confiabilidade para dimensionamento do biodigestor. 


\section{RESULTADOS E DISCUSSÃO}

Ressalta-se que, o prédio apresenta coleta e transporte de esgoto adequado, tornando sustentável quanto aos recursos hídricos requeridos após tratamento. $O$ sistema implantado é constituído por conjunto de motor bomba que coleta os efluentes gerados, direcionando-o para uma peneira estática, que irá remover os particulados sólidos superiores a $0,5 \mathrm{~mm}$. Depois de passar pela peneira, o efluente escoa para o tanque isolado termicamente para que ocorra o processo de digestão anaeróbia com eficiência, tal compartimento é caracterizado como duto de aproximadamente $500 \mathrm{~mm}$ de diâmetro perfurado no solo a uma profundidade aproximada de 5 metros, conectado a um tanque localizado sob o solo, medindo aproximadamente $6 \mathrm{~m}^{3}$, tais dimensões são projetadas para tratamento superior ao número total de habitantes. Posteriormente, quando o efluente sai do segundo tanque, vai para o polimento final, constituído por flotador físico-químico, filtro de areia, e finalmente cloração para remoção de patógenos. Esse sistema é dimensionado para tratamento com vazão $5 \mathrm{~m}^{3} / \mathrm{h}$.

Na tabela 01, estão apresentados os dados referente a produção anual de efluentes doméstico, a estimativa teórica de produção de biogás a partir do processo anaeróbio e o potencial energético ao ano.

\begin{tabular}{lccc}
\hline Tipo de Resíduo & $\begin{array}{c}\text { Produção anual de } \\
\text { resíduos em }\left(\mathrm{m}^{3}\right)\end{array}$ & $\begin{array}{c}\text { Potencial de } \\
\text { Biogás em }\left(\mathbf{m}^{3}\right)\end{array}$ & $\begin{array}{c}\text { Potencial } \\
\text { energético } \\
\text { (KWh/ano) }\end{array}$ \\
\hline Efluente doméstico & 11.972 & $4.549,36$ & $6.505,58$
\end{tabular}

Tabela 01:Estimativa de potencial energético a partir do Biogás Fonte: autores

O gerador de energia elétrica a partir do biogás deve estar localizado próximo ao tratamento do efluente, tendo em vista que a energia produzida será diretamente utilizada para a iluminação de ambientes internos dos apartamentos e para o funcionamento de aparelhos eletrodomésticos dos diversos tipos, tais como ventilador, máquina de lavar, televisão.

O biodigestor para o prédio de 20 andares, será necessário que a disponibilidade do biogás no gerador de energia seja suficiente para produzir energia. Nesta perspectiva é necessário geração de efluente doméstico diário e em grande concentração para que o sistema ocorra com exatidão e eficiência.

A instalação do biodigestor deve ocorrer em local estratégico ao lado das instalações do projeto de tratamento de esgoto. Concomitantemente, o gerador de energia deve estar em localidade próxima. Assim, faz-se necessário a disponibilidade de uma vasta área no pavimento térreo do edifício para que o sistema completo de sustentabilidade ambiental seja empreendido.

Calculou-se prospectivamente a curva de vazão do biogás para dez anos, de 2018 até 2028. Os potenciais estimados individualmente, quando agregados, somam 65.055,84 KWh de "potência instalada" em biogás gerado pela decomposição dos resíduos domésticos , que poderia abastecer uma população de 50 mil de habitantes. Tal potência representa abundância do combustivel biogás, renovável

De acordo com a aplicabilidade do biogás no suprimento de energia elétrica dos aparelhos eletrodomésticos nos apartamentos, como ferro de passar, televisão, liquidificador, máquina de lavar, entre outros, sua produção implicará na constante deposição de resíduos, para que não ocorra o interrompimento na geração de gás pelo biodigestor. Para isso, os modelos a serem escolhidos do digestor anaeróbio, serão os de formação contínua, chinês ou indiano.

\section{CONCLUSÃO}

Mediante a pesquisa realizada e os dados relatados anteriormente, é óbvia a necessidade da busca cada vez maior por fontes renováveis, sejam elas a energia eólica, a energia solar, a energia gerada nos biodigestores, entre tantas outras opções disponiveis.

Contudo, a produção de energia elétrica a partir de dejetos, além de ser acessível a população - podendo instalar biodigestores tanto em casas e prédios, que geralmente não possuem vasta área para a atividade, como também no meio rural, em sítios e fazendas - é também de teor econômico relativamente barato, se comparado a outros meios de geração de energia limpa.

Além de disponibilizar energia alternativa aos moradores, fazendo com que o consumo de energia elétrica comprada seja reduzido e ainda haja um melhor aproveitamento de produtos que seriam destinados aos lixões, ao fim do processo no biodigestor, as sobras servem como fertilizantes que, geralmente, são utilizados em plantações.

Portanto, a maior participação de biogás gerado pelos biodigestores anaeróbios na matriz energética brasileira, acarreta além da menor dependência de energia elétrica comprada, uma menor irradiação de gases poluentes na atmosfera, favorecendo o bem estar e a saúde da sociedade. 


\section{REFERÊNCIAS}

ABRELPE, ASSOCIAÇÃO BRASILEIRA DE EMPRESAS DE LIMPEZA PÚBLICA E RESÍDUOS ESPECIAIS. Panorama dos resíduos sólidos no Brasil: 2016. Rio de Janeiro, 2017. Disponível em: <http://www.abrelpe.org.br/panorama_apresentacao.cfm>. Acesso em: 09 fev. 2018.

DE BAERE, L.; MATTHEEUWS, B. State-of-the-art 2008 - Anaerobic Digestion of Solid Waste. Waste Management World. v.9, N. 4, Julho 2008. p. 8. Disponível em: < http://www.waste-management-world.com/index/display/article-display/339836/articles/waste-management-world/volume-9/issue 4/ features/state-of-the-art-2008-anaerobic-digestion-of-solid-waste.html>.

JUNIOR, Gilson Barbosa Athayde; BESERRA, Leila Brunet Sá; FAGUNDES, Giulliano Souza. Estimando a geração de resíduos sólidos domiciliares a partir do consumo de água em edifícios multifamiliares. Revista Tecnologia, v. 29, n. 2, 2009.

CHERNICHARO, C.A.L. Princípios do tratamento biológico de águas residuárias: Reatores Anaeróbios. 2a.ed. Belo Horizonte: Departamento de engenharia Sanitária e Ambiental, 2007.

BENINCASA, M. ; ORTOLANI, A.F. ; JUNIOR, J.L. Biodigestores convencionais. Jaboticabal: Faculdade de Ciências Agrárias e Veterinárias, Universidade Paulista, 1991. 25p

STAISS, C.; PEREIRA, H. Biomassa Energia Renovável na Agricultura e no Setor Florestal Instituto Superior de Agronomia, Portugal, Revista Agros n. 01 pp. 21-28, 2001.

CEMPRE, Compromisso empresarial para reciclagem, disponível em: http://www.cempre.org.br/ Energia.php, com acesso em 24 de setembro 2017.

EMBRAPA, Empresa Brasileira de Pesquisa Agropecuária, disponível em: <http://www.cnpsa.embrapa.br>, com acesso em setembro de 2017.

DEGANUTTI, Biodigestores rurais: modelo indiano, chinês e batelada.. In: ENCONTRO DE ENERGIA NO MEIO RURAL, 4., 2002, Campinas. Anais elétricos... Disponível em: <http://www.proceedings.
scielo.br/scielo.php?script=sci_arttext\&pid=MSC0000000022002000100031\&lng=pt\&nrm=abn>. Acesso em: setembro de 2017.

McINERNEY, M.J., BRYANT, M.P., Metabolic stages and energetic of microbial anaerobic digestion. In: International Symposium on anaerobic digestion, 1, 1979, University College. Proceedings... London: Applied Science, 1980, p.91- 98.

SILVA, L. L, et al. Princípios de termoelétricas em pequenas propriedades rurais. In: $2^{\circ}$ International workshop advances in cleaner production. São Paulo, maio de 2009.

COSTA et al. Produção de Energia Elétrica a partir de Resíduos Sólidos Urbanos, Trabalho de Graduação Interdisciplinar/ FAAP, São Paulo, 2001.

COSTA, D. F. Geração de energia elétrica a partir do biogás do tratamento de esgoto. Dissertação(Mestrado em Energia) - Universidade Federal de São Paulo (USP), 2006. Disponível em: <www.energia.usp.br/?q=pt-br/produção-técnico / teses-2006>. Acesso em: ago. 2017.

JÚNIOR, J.; SOUZA, C. de F. Construção e operação de biodigestores. Viçosa-MG, CTP, 2009.

ALVES, S. M.; MELO, C.F.M.; WISNIEWISKI, A. Biogás: uma alternativa de energia no meio rural. Belém, EMBRAPA/CPATU. (Miscelânea, 4), 2009.

GASPAR, R. M. B. L. Utilização de Biodigestor em Pequenas e Médias Propriedades Rurais com Ênfase na Agregação de Valor: Um Estudo de Caso na Região de Toledo-PR, 2003. 106f. Dissertação (Mestrado em Engenharia de Produção)- Faculdade de Engenharia de produção e sistemas, Universidade Federal de Santa Catarina, Florianópolis-SC, 2003.

SILVA, L. L, et al. Princípios de termoelétricas em pequenas propriedades rurais. In: $2^{\circ}$ International workshop advances in cleaner production. São Paulo, maio de 2009.

INSTITUTO BRASILEIRO DE GEOGRAFIA E ESTATÍSTICA (IBGE). Censo 2017. Publicado em:2017. Disponível em <http://biblioteca.ibge.gov.br/visualizacao/periodicos/51/agro_2016.pdf>. Acesso em: mar. 2017. 
BARRERA, Paulo, Biodigestores - Energia, Fertilidade e Saneamento Para Zona Rural - São Paulo - Ícone, 1993.

Analise de viabilidade de implantação de biodigestor na Volkswagen do Brasil, acessado em 23 de setembro de $2013<$ http://www.iee.usp.br/biblioteca/producao/2010/Monografias/Monografia_ Biodigestor_Final_CIRO_ev_final.pdf>

POMPERMAYER, Raquel de Souza; PAULA JUNIOR, Durval Rodrigues de. Estimativa do potencial brasileiro de produção de biogás através da biodigestão da vinhaça e comparação com outros energéticos. In: Proceedings of the 3. Encontro de Energia no Meio Rural. 2000.

\section{AUTORES}

ORCID: https://orcid.org/0000-0002-7920-4107

VANESSA ROSALES BEZERRA. | Universidade Estadual da Paraíba | PPGCTA - Mestrado em Ciências e Tecnologia Ambiental | Campina Grande, PB. Brasil | Correspondência para: Rua Juvêncio Arruda, S/N - CEP: 58429-600 - Campus Universitário, Bodocongó - Campina Grande - PB | E-maill: rosalesuepb@gmail.com

\section{ORCID: https://orcid.org/0000-0002-1462-5963}

LUIS REYES ROSALES MONTERO, DR. | Universidade Federal de Campina Grande | DEE - Engenharia Elétrica | Campina Grande, PB. Brasil | Correspondência para: Rua Aprígio Veloso, 882 - Bairro Universitário - Campina Grande - PB CEP 58429-900 | E-maill: professorluis@hotmail.com

ORCID: https://orcid.org/ 0000.0001.5861.7407

VALDERI DUARTE LEITE, DR. | Universidade Estadual da Paraíba | PPGCTA - Mestrado em Ciências e Tecnologia Ambiental | Campina Grande, PB. Brasil | Correspondência para: Rua Juvêncio Arruda, S/N - CEP: 58429-600 - Campus Universitário, Bodocongó - Campina Grande - PB | E-maill: mangabeiraleite@hotmail.com

ORCID: https://orcid.org/ 0000-0001-7894-5248

KELY DAYANE SILVA DO 0́. | Universidade Estadual da Paraíba | PPGCTA - Mestrado em Ciências e Tecnologia Ambiental | Campina Grande, PB. Brasil | Correspondência para: Rua Juvêncio Arruda, S/N - CEP: 58429-600 - Campus Universitário, Bodocongó - Campina Grande - PB | E-maill: kelidayane@gmail.com

\section{COMO CITAR ESTE ARTIGO}

BEZERRA, Vanessa Rosales; MONTERO, Luis Reyes Rosales; LEITE, Valderi Duarte; SILVA DO Ó, Kely Dayane. Aproveitamento Energético Através do Biodigestor e sua Implantação em Prédios de 20 Andares. MIX Sustentável, [S.I.], v. 4, n. 3, p. 89-96, out-mar. 2018. ISSN 24473073. Disponível em: <http://www. nexos.ufsc.br/index.php/mixsustentavel>. Acesso em: dia mês. ano. doi:https://doi.org/10.29183/2447-3073. MIX2018.v4.n3.89-96.

DATA DE ENVI0: 04/07/2018

DATA DE ACEITE: 05/09/2018 